\title{
CURSO DE PEDAGOGIA EM CENÁRIO DE (CONTRA)REFORMA: CONCEPÇÕES DE FORMAÇÃO DE PROFESSORES EM DISPUTA
}

Pedagogy course in (against) reform: conceptions of teacher training in dispute

Curso de pedagogía en (contra) la reforma: concepciones de formación de profesores en disputa

Andressa Graziele Brandt*

Márcia de Souza Hobold**

Isabel Maria Sabino de Farias***

https://doi.org/10.38117/2675-181X.formov2021.v3i1n5.50-70.

\section{Resumo}

As análises deste texto têm como objetivo problematizar o movimento de disputa entre a concepção de formação de professores manifestada na Resolução CNE/CP n ${ }^{\circ} 1 / 2006$, que instituiu Diretrizes Curriculares Nacionais para o Curso de Graduação em Pedagogia, e na Resolução CNE/CP no 2/2019, que define as Diretrizes Curriculares Nacionais para a Formação Inicial de Professores para a Educação Básica e institui a Base Nacional Comum para a Formação Inicial de Professores da Educação Básica (BNC-Formação). O exame do tema, de natureza qualitativa, contou com dados bibliográficos e documentais. A reflexão assume o seguinte questionamento: quais os possíveis diálogos, resistências e conflitos atravessam a atual política curricular para o Curso de Pedagogia, ou seja, para a formação de professores no Brasil? Subsidiam o exame as formulações Brandt e Hobold $(2019,2020)$, Dourado (2007, 2015), Farias (2006, 2019), Saviani (2007), Scheibe e Durli (2011) e outros.

Palavras-chave: Curso de Pedagogia; Formação de professores; Diretrizes Curriculares; Políticas curriculares. 
Curso de Pedagogia em cenário de (contra)reforma: Concepções de formação de professores em disputa

\begin{abstract}
The analyzes of this text aim to problematize the movement of dispute between the conception of teacher education expressed in Resolution CNE/CP $\mathrm{n}^{\circ} 1 / 2006$, which instituted National Curricular Guidelines for the Undergraduate Course in Pedagogy, and in Resolution CNE/CP n ${ }^{\circ}$ 2/2019, which defines the National Curriculum Guidelines for the Initial Training of Teachers for Basic Education and establishes the Common National Base for the Initial Training of Teachers of Basic Education (BNC-Formation). The qualitative examination of the topic included bibliographic and documentary data. The reflection assumes the following question: what are the possible dialogues, resistances and conflicts that cross the current curriculum policy for the Pedagogy Course, that is, for the training of teachers in Brazil? The exams are supported by the formulations Brandt and Hobold (2019, 2020), Dourado (2007, 2015), Farias (2006, 2019), Saviani (2007), Scheibe e Durli (2011) and others.
\end{abstract}

Keywords: Pedagogy Course; Teacher education; Curricular guidelines; Curricular policies.

\title{
Resumen
}

Los análisis de este texto tienen como objetivo problematizar el movimiento de disputa entre la concepción de formación docente expresada en la Resolución CNE / CP n 1/2006, que instituyó los Lineamientos Curriculares Nacionales para la Licenciatura en Pedagogía, y en la Resolución CNE/CP n²/2019, que define los Lineamientos Curriculares Nacionales para la Formación Inicial de Docentes de Educación Básica y establece la Base Nacional Común para la Formación Inicial de Docentes de Educación Básica (BNC-Formación). El examen cualitativo del tema incluyó datos bibliográficos y documentales. La reflexión asume la siguiente pregunta: ¿Cuáles son los posibles diálogos, resistencias y conflictos que atraviesan la política curricular actual para el Curso de Pedagogía, es decir, para la formación de docentes en Brasil? Los exámenes están respaldados por las formulaciones Brandt y Hobold (2019, 2020), Dourado (2007), Farias (2006, 2019), Saviani (2007), Scheibe e Durli (2011) y otros.

Palabras clave: Curso de Pedagogía; Formación de profesores; Lineamientos curriculares; Políticas curriculares. 


\section{Introdução}

As análises deste texto têm como objetivo problematizar o movimento de disputa entre as concepções de formação de professores manifestadas na Resolução ${ }^{\circ}{ }^{\circ}$, de 15 de maio de 2006, editada pelo Conselho Pleno (CP) do Conselho Nacional de Educação (CNE), que instituiu Diretrizes Curriculares Nacionais para o Curso de Graduação em Pedagogia (DCNCLPe), e na Resolução CNE/CP nº 2, de 20 de dezembro de 2019, que define as Diretrizes Curriculares Nacionais para a Formação Inicial de Professores para a Educação Básica (DCNFIEB) e institui a Base Nacional Comum para a Formação Inicial de Professores da Educação Básica (BNC-Formação).

Percebe-se que as discussões acerca das políticas curriculares para a Educação Básica e, consequentemente, para o campo da formação de professores ressurgiram com maior intensidade a partir do golpe jurídico-midiático-parlamentar de 2016, quando ocorreu, por parte dos agentes internos e externos que representam a agenda neoliberal, a elaboração e aprovação de um currículo mínimo e prescritivo para as diferentes etapas da escolarização e, portanto, uma voraz tentativa de implantar essas políticas nos cursos de licenciatura. Firma-se no campo da formação de professores uma arena de disputas entre projetos educativos de classe, a partir da qual a burguesia pretende aumentar a mais-valia e manter a hegemonia por meio do aumento da produtividade e da internalização do projeto educativo capitalista. É clara a interferência neoliberal nos rumos da escola básica e da formação de professores, cujos objetivos vêm sendo manipulados e camuflados por meio de políticas curriculares.

Com base no exame de documentos e pesquisas acerca das reformas educacionais na América Latina, Ball (2016), Dourado (2007), Shiroma e Evangelista (2011), Freitas (2012, 2015), Frigotto (2011) e Hypolito (2015), entre outros pesquisadores do campo das políticas curriculares e educacionais, afirmam que há similaridade entre as indicações de organismos multilaterais (OM), como o Banco Mundial (BM), a Organização das Nações Unidas para a Educação, a Ciência e a Cultura (Unesco), a Organização para a Cooperação e Desenvolvimento Econômico (OCDE), o Programa das Nações Unidas para o Desenvolvimento (PNUD), e as políticas implantadas por países subdesenvolvidos, a exemplo do Brasil.

Corrobora-se o argumento de Evangelista (2012) de que, para uma leitura fundamentada do mundo, é necessário um aporte teórico que favoreça análises objetivas do real objetivo e do seu contexto, pois é impossível refletir sobre a posição do sujeito e a do objeto sem referências à mediação teórica. Sendo assim, o exame do tema em foco neste escrito - o movimento de disputa entre concepções de formação de professores no 
âmbito do Curso de Pedagogia - recorreu a dados documentais e bibliográficos e foi realizado com apoio nos pressupostos da abordagem qualitativa de pesquisa (NÓBREGA-THERRIEN; FARIAS; SALES, 2010). Além do corpus documental, constituído pelas Resoluções do CNE/CP n 1/2006 e nº 2/2019, a análise encontra suporte nas contribuições teóricas de autores nacionais que têm discutido o tema, a exemplo de Brandt e Hobold (2019, 2020), Dourado (2007), Farias (2006, 2019), Frangella (2020), Freitas (2012), Saviani (2007), Scheibe e Durli (2011), entre outros.

Argumenta-se que, embora a constituição histórica do Curso de Pedagogia (CPe) seja marcada por intensos debates e polêmicas, as definições trazidas pela Resolução $\mathrm{CNE} / \mathrm{CP} \mathrm{n}^{\circ} 1 / 2006$, ainda que não tenham dirimido todos os dissensos, acolheram anseios expressivos do movimento dos educadores progressistas. É com base nessa premissa que se problematizam as DCNFIEB e a BNC-Formação, instituídas pela Resolução CNE/CP $n^{\circ} 2 / 2019$, que atingem frontalmente as orientações vigentes no CPe desde 2006, em virtude de seu alinhamento à Base Nacional Comum Curricular (BNCC). Nessa perspectiva, a reflexão assume como preocupação central o seguinte questionamento: quais os possíveis diálogos, resistências e conflitos que atravessam a atual política curricular para o Curso de Pedagogia, ou seja, para a formação de professores no Brasil?

Dessa maneira, em vista da indagação que move a análise, apresenta-se, inicialmente, uma contextualização da constituição curricular do CPe, por meio dos seus quatro marcos legais, bem como das concepções sobre a formação de professores presentes em cada um desses documentos da política curricular. Além desta parte introdutória, que aborda as concepções de formação de professores, o artigo também está estruturado com os seguintes eixos: concepção de formação de professores nas políticas curriculares destinadas ao $\mathrm{CPe}$; análise do $\mathrm{CPe}$ no âmbito da Resolução $\mathrm{CNE} / \mathrm{CP} \mathrm{n}^{\circ}$ 2/2019; e, por fim, as considerações finais.

\section{Concepção de formação de professores nas políticas curriculares para o Curso de Pedagogia no Brasil}

Ao longo dos oitenta anos do CPe no Brasil, seu currículo foi constituído por meio de quatro marcos legais, cujas concepções de formação são atravessadas por aspectos históricos desafiadores no que tange à formação do pedagogo: a relação entre os pontos de profissionalização e de qualificação dos profissionais da educação; a superação da dicotomia entre teoria e prática, da separação entre ensino e pesquisa, bem como da formação dos estudantes no bacharelado e na licenciatura; a falta de integração entre as 
disciplinas de conteúdo específico e as disciplinas pedagógicas; e o distanciamento existente entre a formação acadêmica e a realidade encontrada pelos professores no contexto das escolas (BRANDT; HOBOLD, 2019).

Nesse sentido, em relação ao primeiro currículo do $\mathrm{CPe}$, proposto pelo DecretoLei n ${ }^{\circ} 1.190$, de 4 de abril de 1939, a concepção de formação de professores foi baseada em um modelo profissionalizante e técnico-científico moldado por meio de um currículo rígido, a ser conhecido como o "Esquema 3+1", elaborado com princípios tradicionais e constituído por disciplinas prescritas, com uma organização curricular seriada, visou formar o Técnico em Educação e o pedagogo-professor, no qual o professor era um mero transmissor de conhecimento, e os alunos excelentes receptores e reprodutores do conhecimento transmitido (BRANDT; HOBOLD, 2020).

Por meio do Parecer n ${ }^{\circ}$ 251/1962, foi instituído o segundo currículo do CPe, que, com esteio em uma concepção tecnicista e de formação fragmentada e generalista, visou formar profissionais para atuação como professor primário com atuação de $1^{\mathrm{a}}$ à $4^{\mathrm{a}}$ séries, bem como para gestão, com habilitações em orientação, supervisão e administração. Prevalece ainda um currículo que cinde a formação do pedagogo entre o bacharelado e a licenciatura.

Anos depois, por meio do Parecer n ${ }^{\circ}$ 252/1969 e da Resolução CFE nº 2/1969, foi instituído seu terceiro currículo, o qual, embora continuasse com uma concepção tecnicista e fragmentada de formação, experimentou certo avanço ao extinguir o bacharelado da formação do pedagogo, firmando o CPe como licenciatura. Esse marco legal, de vigência duradoura, não impediu, contudo, a insurgência, na práxis das instituições formadoras e de seus educadores, de outras concepções de formação. Assim, se na década de 1970 prevaleceu uma concepção de formação voltada para o treinamento do técnico da educação, introduzindo as habilitações para formar o Orientador Educacional, Supervisor, Administrador e Inspetor Escolar. Na primeira metade dos anos 1980 observa-se uma ênfase na formação do educador; e nos anos 1990, um redirecionamento para o professor-pesquisador reflexivo, além de uma concepção produtivista, fortemente influenciada pela pedagogia das competências (DINIZPEREIRA, 2000).

Com relação aos conflitos e debates históricos pertinentes à identidade do CPe no Brasil, Brandt e Hobold (2019) afirmam que, dos quase trinta anos de vigência do Parecer CFE no 252/1969, pelo menos a última década foi marcada por um forte movimento de discussão dessa identidade e da necessidade de reformulação do Curso, culminando em um amplo processo de debates e tensionamentos entre estudantes, educadores e 
Curso de Pedagogia em cenário de (contra)reforma: Concepções de formação de professores em disputa

instituições educacionais - a exemplo da Associação Nacional de Pós-Graduação e Pesquisa em Educação (ANPEd), da Associação Nacional pela Formação dos Profissionais da Educação (Anfope), do Fórum dos Diretores das Universidades e das Faculdades de Educação das Universidades Públicas Brasileiras (Forumdir), do Conselho Nacional de Educação (CNE) e do Movimentos dos Educadores, etapa significativa da constituição histórica do CPe no país.

Um desdobramento desse amplo debate em torno da concepção de formação de professores, em particular da formação do pedagogo, que permeou a sociedade brasileira e a comunidade acadêmica, sobretudo no final dos anos 1990 e início dos anos 2000, foi a afirmação da docência como seu foco principal (ANFOPE, 2016). Em seu sentido social, docência é o trabalho do professor, cuja tarefa profissional envolve a mediação pedagógica do processo de ensino e de aprendizagem (FARIAS et al., 2014), pressupondo que esta atribuição se modifica em face das condições de trabalho e dos desafios que são postos a esses profissionais da educação a cada momento histórico. Este é um delineamento importante, uma vez que evidencia o reconhecimento do pedagogo como um profissional docente, ideia que se firmará em dispositivo legal gestado e aprovado nos primeiros anos do século XXI, mais precisamente a Resolução CNE/CP n ${ }^{\circ}$ 1/2006 (BRASIL, 2006b), que estabelece o quarto currículo do CPe. Nesse marco regulatório, o que se sobressai é a assunção da formação para a docência como tônica da concepção de formação do pedagogo.

O CPe, desde então, é destinado à formação inicial de professores para a docência na Educação Infantil e nos Anos Iniciais do Ensino Fundamental; de profissionais para a gestão educacional e atuação em espaços escolares e não escolares; de professores que atuarão no Curso Normal de nível médio; e de profissionais para as demais atividades do campo educacional em que sejam previstos conhecimentos pedagógicos. Nos termos como é explicitada no art. $4^{\circ}$, as DCNCLPe evidenciam a abrangência da função de magistério do pedagogo (BRASIL, 2006b). Nesse sentido, além de reconhecer a docência como base da formação do professor-pedagogo, concebida numa perspectiva polivalente, de caráter multidisciplinar e amplo, as DCNCLPe demarcam e legitimam o campo de atuação desse profissional, considerando sua práxis histórica.

Esta definição, por muitos interpretada como avanço, também tem sido questionada ao longo dos catorze anos de vigência desta DCN (BRASIL, 2006b). Vários estudos acadêmicos têm expressado descontentamento com a formação polivalente (PIMENTA et al., 2017; HOBOLD et al., 2009), evidenciando, a partir da análise do Projeto Pedagógico de Cursos (PPC) de Licenciaturas em Pedagogia (LPe), reformulados 
em todo o país à luz da Resolução CNE/CP n 1/2006, uma indefiniçãa em relação ao perfil profissional do egresso desse curso, ou seja, não há concordância sobre a identidade do licenciado em Pedagogia.

Para além dessas críticas, cabe frisar que a Resolução CNE/CP n ${ }^{\circ}$ 1/2006 postula uma concepção de formação larga, referenciada em uma formação teórica articulada pela docência, a pesquisa, a gestão, bem como o desenvolvimento do pensamento crítico e contextualizado. Esta acepção se explicita ainda mais nos conhecimentos profissionais fundamentais à formação do licenciado pedagogo: I) o conhecimento da escola como organização complexa, que tem a função de promover a educação para e na cidadania; II) a pesquisa, a análise e a aplicação dos resultados de investigações de interesse da área educacional; III) a participação na gestão de processos educativos e na organização e funcionamento de sistemas e instituições de ensino (BRASIL, 2006b, art. $3^{\circ}$, inc. I, II e III). Definem-se, em consonância com esses conhecimentos profissionais, as atividades da docência, da pesquisa e da gestão como base de atuação profissional do egresso da Licenciatura em Pedagogia (BRASIL, 2006b, art. $4^{\circ}$ ), prevista para a Educação Infantil e Anos Iniciais do Ensino Fundamental, além da gestão e de espaços escolares e não escolares, bem como nas demais atividades do campo educacional que demandem conhecimento pedagógico. O perfil profissional do egresso da Pedagogia, aliás, foi tema de acirrado debate durante a tramitação da DCNCLPe/2006, foi decisiva na definição do foco da formação do pedagogo.

Outro aspecto de tensão nas DCNCLPe/2006 é que elas não definem conteúdos obrigatórios para a formação, apresentando somente orientações gerais acerca da sua organização curricular, sob o argumento da necessidade de respeitar a diversidade nacional e a autonomia pedagógica das instituições. É justamente a esse aspecto que se dirige a crítica tecida por Saviani (2007, p. 127) um ano após a aprovação dessa diretriz, na qual destaca que elas são "extremamente restritas e demasiadamente extensivas: muito restritas no essencial e assaz excessivas no acessório". Para o autor, são restritas no que concerne "[...] àquilo que configura a Pedagogia como um campo teórico-prático dotado de um acúmulo de conhecimentos e experiências resultantes de séculos de história"; ao mesmo tempo, são extensivas porque "[...] se dilatam em múltiplas e reiterativas referências à linguagem hoje em evidência, impregnada de expressões como conhecimento ambiental-ecológico pluralidade de visões de mundo; interdisciplinaridade, contextualização, democratização; ética [...]”.

Com efeito, ao longo desses últimos catorze anos, o texto das DCNCLPe/2006 acumulou várias críticas, as quais recaem, entre outros aspectos, sobre os componentes/o conteúdo da formação, deixado a cargo de cada IES, de modo que "[...] não é fácil 
identificar na Resolução do CNE uma orientação que assegure um substrato comum em âmbito nacional a dar um mínimo de unidade ao referido curso" [...] (SAVIANI, 2007, p. 127).

Vale lembrar que a configuração curricular das DCNCLPe/2006 derivou de intensos debates e negociações entre as entidades do campo educacional, o CNE e intelectuais, com concepções distintas. Para além de suas ambiguidades, não se pode perder de vista que os elementos dessas diretrizes, ao romperem com enfoques curriculares calcados no bacharelado e em habilitações técnicas específicas, propiciaram um desenho curricular fundamentado em uma concepção de formação de professores sócio-histórica, ainda que tensionado pela racionalidade técnica que representa a lógica neoliberal.

Assim, entre conquistas e permanências, a Resolução CNE/CP no 1/2006 constituiu o quarto desenho curricular do $\mathrm{CPe}$, logrando o reconhecimento da docência como base da formação do pedagogo. Estabeleceu-se um currículo permeado por uma concepção de formação de caráter sócio-histórico, com carga horária mínima de 3.200 horas, distribuídas em 2.800 horas de atividades formativas, 300 horas de estágio supervisionado no decorrer do curso e 100 horas de atividades teórico-práticas de aprofundamento. Por um lado, essa diretriz evidenciou esforço para expressar, no currículo do $\mathrm{CPe}$, uma perspectiva integradora entre teoria e prática a partir da proposição do estágio curricular, com 300 horas, das 100 horas de atividades teórico-práticas de aprofundamento e do indicativo de fundamentos metodológicos em todo o percurso formativo do licenciando; por outro, porém, também abriu caminho para uma visão pragmatista da prática.

Os tensionamentos em torno do processo de formação por meio do estágio curricular explicitaram, de certo modo, esse movimento, ao demandar que sua realização, ao longo do curso, assegurasse ao licenciando experiência de exercício profissional em ambientes escolares e não escolares, precisamente: a) na Educação Infantil e nos Anos Iniciais do Ensino Fundamental, prioritariamente; b) nas disciplinas pedagógicas dos cursos de Ensino Médio, na modalidade Normal; c) na Educação Profissional, na área de serviços e de apoio escolar; d) na Educação de Jovens e Adultos (EJA); e) na gestão; f) em reuniões de formação pedagógica (BRASIL, 2006b, art. $8^{\circ}$, inc. IV). Tal orientação trouxe desafios a mais, com sobrecarga para a formação dos estudantes, uma vez que, nesses contextos, imersões como o estágio requerem a apropriação de aportes teóricos e empíricos diferentes. 
Essa política curricular, delineada sob forte influência do pensamento neoliberal em âmbito nacional, não se fez, contudo, sem conflitos e resistências ${ }^{1}$, que estiveram presentes ao logo dos últimos catorze anos de sua concretização. Ao analisar esse processo, Triches (2016) enfatiza a relação orgânica entre a reforma do Curso de Pedagogia e as políticas e estratégias econômicas e educacionais implementadas no Brasil à época, iniciativa articulada internacionalmente visando à construção de um consenso em torno da reforma educacional, particularmente da formação docente. Desse modo, as mudanças no $\mathrm{CPe}$, articuladas com as do mundo do trabalho, em razão da reestruturação produtiva e da reconversão laboral e docente, concretizaram a nova pedagogia da hegemonia, permeada pelas concepções da Teoria do Capital Humano, da Pedagogia do Aprender a Aprender, da responsabilização do professor, da reconversão docente e do gerencialismo (EVANGELISTA; TRICHES, 2012).

Nessa direção, Brandt e Hobold (2019) ponderam que, embora a Resolução $\mathrm{CNE} / \mathrm{CP} \mathrm{n}^{\mathrm{o}}$ 1/2006 apresente uma concepção de professor sócio-histórica, sua proposta curricular, na essência, favorece uma formação reducionista do papel do pedagogo professor, de caráter generalista, a qual é reflexa das distintas reivindicações por parte das entidades envolvidas no processo de discussão e formulação desses documentos. Assim sendo, mostra-se oportuna a reflexão de Diniz-Pereira (2000, p. 52) a respeito do fato de que "[...] as mudanças na maneira de se pensar a formação de professores não garantem", necessariamente, "[...] mudanças, alterações e inovações imediatas nos cursos de formação docente, especificamente nas licenciaturas", pois, como revela a história da formação de professores no Brasil, a efetivação de mudanças nesse âmbito é lenta e parece seguir um caminho mais complexo, que envolve "[...] uma construção que é, ao mesmo tempo, individual, coletiva e interativa" (FARIAS, 2006, p. 45).

A digressão realizada revela que, no Brasil, a concepção de formação de professores subjacente às políticas curriculares para o $\mathrm{CPe}$ foi historicamente constituída sob forte disputa, evidenciando projetos educativos e de sociedade distintos e em contínuo embate.

\footnotetext{
${ }^{1}$ Uma expressão desses embates encontra-se na carga horária das atividades teórico-práticas, ampliada desde a Resolução CNE/CP n 2 2, de 19 de fevereiro de 2002, para 400 horas de Prática como Componente Curricular (PCC), vivenciadas ao longo do curso. Esta definição difere do que a Resolução no 1/2006 traz, evidenciando a existência de tensão entre a ênfase necessária à dimensão prática no currículo de formação de professores.
} 
Curso de Pedagogia em cenário de (contra)reforma:

Concepções de formação de professores em disputa

\section{Curso de Pedagogia na Resolução CNE/CP n ${ }^{0}$ 2/2019 - a formação para a docência sob ataque}

Como evidenciado, o CPe chegou ao século XXI ainda com sua identidade em questão, tensionamento que ganhou um novo capítulo no ano de 2019, com a aprovação da Resolução CNE/CP n ${ }^{\circ}$ 2, de 20 de dezembro. Publicado no Diário Oficial da União as vésperas das comemorações natalinas (em 23 de dezembro), este texto de dez páginas está estruturado em nove capítulos e trinta artigos, precedidos por cinco considerações prévias, além de mais oito páginas de anexos, configurados em quatro quadros.

Esta Resolução foi encaminhada e aprovada de forma célere e sem ampla discussão com entidades educacionais, pesquisadores, profissionais docentes e estudantes, muito embora seu último "considerando" insinue o contrário, ao fazer menção à elaboração e ao envio ao CNE do texto "Proposta para Base Nacional Comum da Formação de Professores da Educação Básica” para “[...] análise e emissão de parecer e formulação da resolução [...]" (BRASIL, 2020, p. 1). Sobre a produção desse texto curricular, ao examiná-lo Farias (2019) o situa no quadro das ações da contrarreforma da Educação Básica, compreensão reforçada também por Rodrigues, Pereira e Mohr (2020) ao registrarem, no tópico "Pós-escrito", no qual são resumidos os principais acontecimentos que antecederam a aprovação da Resolução $n^{\circ}$ 2/2019 pelo CNE, que ele "mudou" a prática de ampla socialização pública das proposições desse Conselho, vigente desde a democratização do país. "Estamos vivendo um período repleto de golpes e reformas indiretas e, no campo educacional, essas profundas alterações desencadeiam inúmeros retrocessos [...]” (RODRIGUES; PEREIRA; MOHR, 2020, p. 34).

A Resolução CNE/CP nº 2/2019 rompe com a perspectiva de articulação entre formação inicial e continuada, princípio defendido pelo movimento dos educadores nas últimas décadas, no tocante ao modo de conceber e desenvolver políticas curriculares. De igual modo, favorece o acirramento de ideias e pressupostos que, de algum modo, se fizeram presente nas DCNCLPe/2006. Sobre isso, Triches (2016) assevera que é possível perceber, por meio da leitura e da identificação das palavras usadas nesse documento ${ }^{2}$, entre outros aspectos, o alargamento das funções docentes, com abordagem utilitarista, aligeirada e mercantilista.

Assim, percebe-se que, em relação à política educacional brasileira, pouco avançamos ou nada mudou em relação à década anterior, e a educação brasileira está pagando um preço muito caro pelo envolvimento do empresariado produtivista e

\footnotetext{
${ }^{2}$ Para entender melhor o aprofundamento do estudo das palavras nas DCNCLPe, leia: Triches (2016).
} 
financista com os diversos níveis da educação nacional. Como adverte Frigotto (2011), a expansão da lógica privatista do ensino tem não apenas definido, mas também condensado o conhecimento a ser ensinado em apostilas ou manuais que orientam a forma de ensinar, bem como instituído métodos de ensino, critérios e processos de avaliação e controle sobre os estudantes e os professores. Não perder de vista esse movimento é fundamental para compreender como a Resolução CNE/CP $n^{\circ}$ 2/2019, entre outras medidas, instituiu a BNC-Formação.

Em que contexto a Resolução $\mathrm{CNE} / \mathrm{CP} \mathrm{n}^{\circ}$ 2/2019 foi construída? Em meio à Reforma do Ensino Médio e do 'Novo Ensino Médio', à BNCC (BRASIL, 2017), ao Future-se e à Política Nacional de Formação de Professores, esta última apresentada por Maria Helena Guimarães em outubro de 2017, cenário político que permitiu seu surgimento e, ao mesmo tempo, não lhe conferiu forças para se sustentar. Com efeito, a adesão ao 'Neoliberalismo da Terceira Via', em curso desde o governo de Fernando Henrique Cardoso (FHC) e prolongado nas gestões de Lula e Dilma, ainda que por caminhos diversos e mais dialógicos, facilitou e até mesmo incentivou o empresariado a envolver-se com os diversos níveis da educação nacional, inclusive mediante protagonismo acentuado junto ao Ministério da Educação (MEC), por meio do movimento Todos pela Educação, não apenas do ponto de vista estritamente financeiro, mas também político-ideológico.

Questiona-se: não possuem nossos professores formação e autonomia suficientes para a definição de seus currículos e das políticas de currículo deste país? Quem escreveu a proposta da Resolução CNE/CP n $2 / 2019$ ? Segundo Evangelista, Fiera e Titton (2019), essa diretriz foi escrita por membros do CNE que têm estreita relação com a esfera privada, a qual também é sustentada por autores com vínculos institucionais com a Comissão Bicameral, cujos ideais estão ligados ao movimento empresarial, em especial às organizações do mercado privado das escolas superiores, conforme também denunciaram Farias (2019) e Rodrigues, Pereira e Mohr (2020).

O contexto brevemente sumariado explica o pleno alinhamento da Resolução $\mathrm{CNE} / \mathrm{CP}$ n$^{\circ}$ 2/2019 à BNCC da Educação Básica. Destaca-se que, infelizmente, em mais de um momento desse texto curricular, é ressaltada a necessidade de a formação docente seguir os princípios das competências gerais da BNCC. Este conceito, aliás, é definido nesse documento como [...] a mobilização de conhecimentos (conceitos e procedimentos), habilidades (práticas, cognitivas e socioemocionais), atitudes e valores para resolver demandas complexas da vida cotidiana, do pleno exercício da cidadania e do mundo do trabalho. (BRASIL, 2018, p. 8). 
Curso de Pedagogia em cenário de (contra)reforma:

Concepções de formação de professores em disputa

A DCN n ${ }^{\circ}$ 2/2019 trata exclusivamente da formação inicial de professores, organizando o currículo em 3.200 horas, distribuídas em três grupos, conforme detalhado no Quadro 2.

Quadro 2: Currículo e carga horária da Resolução CNE/CP nº 2/2019

\begin{tabular}{|l|l|l|}
\hline \multicolumn{1}{|c|}{ Grupo I (800h) } & \multicolumn{1}{|c|}{ Grupo II (1.600h) } & \multicolumn{1}{c|}{ Grupo III (800h) } \\
\hline $\begin{array}{l}\text { Para a base comum, que } \\
\text { compreende os conhecimentos } \\
\text { científicos, educacionais e }\end{array}$ & $\begin{array}{l}\text { Para a aprendizagem dos } \\
\text { conteúdos específicos das } \\
\text { pedagógicos que fundamentam a }\end{array}$ & $\begin{array}{l}\text { Para a prática pedagógica, } \\
\text { com a seguinte distribuição: } \\
\text { temáticas e objetos de }\end{array}$ \\
$\begin{array}{l}\text { educação e suas articulações com } \\
\text { os sistemas, escolas e práticas } \\
\text { educacionais. }\end{array}$ & $\begin{array}{l}\text { conhecimento da BNCC para os componentes } \\
\text { o domínio pedagógico desses } \\
\text { conteúdos. }\end{array}$ & $\begin{array}{l}\text { curriculares dos Grupos I e II, } \\
\text { distribuídas ao longo do } \\
\text { curso, desde o início. }\end{array}$ \\
\hline
\end{tabular}

Fonte: Elaborado pelas autoras com base na Resolução CNE/CP n 2/2019.

Cabe destacar que as 200 horas de atividades teórico-práticas de aprofundamento em áreas específicas de interesse dos estudantes, conforme núcleo definido no inciso III do artigo 12 da Resolução CNE/CP n 0 02/2015 (BRASIL, 2015), por meio da iniciação científica, da iniciação à docência, da extensão e da monitoria, entre outras, consoante ao PPC da instituição, desaparecem na BNC-Formação (BRASIL, 2020). Este desaparecimento pode ser um forte indício de que uma formação mais integral dos licenciandos não foi considerada, ou seja, a participação em atividades do núcleo de estudos integradores para enriquecimento curricular deixa de fazer parte de uma formação mais ampla e que estimula a inserção dos futuros professores em outros espaços formativos relevantes.

Outra supressão observada na Resolução do CNE/CP n 2/2019 se refere às atividades complementares, presentes desde 2002 como componente curricular dos cursos de licenciatura, mas que desaparecem na BNC-Formação. Destaca-se a importância destas atividades, também consideradas e defendidas na Resolução CNE/CP $n^{\circ} 1 / 2006$. Preocupa a quase anulação de uma formação mais integral, que valorize os aspectos éticos, estéticos e culturais, bem como a participação em pesquisas, eventos, projetos de monitoria, pesquisa, etc., consolidando uma formação cujos arranjos são condizentes com a perspectiva de desapropriação de um profissional reflexivo, autônomo e atuante criticamente em seu contexto de trabalho. A quem interessa uma formação tão formatada, padronizada e propícia a ser avaliada como esta que foi imposta pela Resolução CNE/CP nº 2/2019?

Outro fator de análise, diferentemente da Resolução CNE/CP nº 01/2006, que define claramente o conceito de docência sob o qual sustenta suas orientações (BRASIL, 
2006b, art. $2^{\circ}, \S 1^{\circ}$ ), constata-se o silenciamento desse construto na Resolução CNE/CP $n^{\circ} 2 / 2019$. Por outro lado, o conceito de competência, fundamento pedagógico da BNCC da Educação Básica, permeia todo o texto da referida Resolução, sendo particularmente abordado no Capítulo I (Do Objeto), o que por si já denota a concepção de formação de professores que ancora essa DCN, isto é, uma concepção técnico-instrumental, de feição utilitarista e reducionista do trabalho do professor.

É justamente essa seção que estabelece que “[...] a formação docente pressupõe o desenvolvimento, pelo licenciando, das competências gerais previstas na BNCCEducação Básica [...]” (BRASIL, 2020, art. 2º, grifos nossos), bem como “[...] o desenvolvimento das correspondentes competências gerais docentes" (BRASIL, 2020, art. $3^{\circ}$, grifos nossos). Estas últimas, em um total de dez, desdobram-se em competências específicas. As competências específicas, por sua vez, abrangem três dimensões: o conhecimento profissional, a prática profissional e o engajamento profissional. Para cada uma das competências específicas são listadas habilidades. Enfim, a formação inicial deve assegurar tanto as competências a serem ensinadas aos discentes da Educação Básica quanto aquelas relacionadas ao exercício profissional.

Segundo Gonçalves, Mota e Anadon (2020), nas DCN para Formação de Professores aprovadas pelo CNE em dezembro de 2019, evidenciam-se um alinhamento com a BNCC (BRASIL, 2017), a retomada coercitiva da definição de competências para a construção dos currículos das licenciaturas e o silenciamento em relação às discussões da formação continuada e da valorização profissional, ou seja, a Resolução CNE/CP $n^{\circ}$ 2/2019 (BRASIL, 2020) é um retrocesso para a formação de professores, uma vez que privilegia uma formação tecnicista, padronizada e pragmática, que desenha, para um futuro muito próximo, um crescente controle sobre o ser e o fazer dos professores e da gestão escolar. Este processo ocorrerá principalmente por meio do sistema de avaliação brasileiro, que a cada dia se aproxima mais aos interesses neoliberais, os quais, como frisado anteriormente, prezam o controle e o individualismo, estimulando a concorrência entre professores, estudantes, escolas e sistemas de ensino, principalmente com o incentivo à meritocracia, por meio da pedagogia das competências (FREITAS, 2012).

Neste aspecto, há uma nítida tendência assumida pelas atuais Diretrizes, qual seja, a de "[...] padronizar o currículo para ter parâmetros para avaliar; assim, o que está a luz da nova proposta curricular não é a qualificação da formação docente, mas a avaliação" (GONÇALVES; MOTA; ANADON, 2020, p. 369). Nesta premissa, a política curricular para professores e gestores, nos moldes em implantação, tem por objetivo a desintelectualização dos profissionais do magistério, a fim de torná-los pragmáticos e diminuir sua capacidade de intervenção consciente. No fim, o que se "[...] pretende é 
Curso de Pedagogia em cenário de (contra)reforma:

Concepções de formação de professores em disputa

forjar uma nova cultura organizacional para a escola, marcada pela potencialização da disputa, do individualismo e da cooperação fabricada" (SHIROMA; EVANGELISTA, 2004, p. 535).

Ao se alinhar a formação para novos currículos como percurso de implementação retoma-se, justamente, a lógica da produtividade da ação docente. Desse modo, a formação reveste-se de um caráter adaptativo, com base na racionalidade técnica, que busca, em uma lógica linear e cumulativa, suprir uma falta - essa sim assumida a priori: a de que não cabe ao professor a possibilidade de pensar em como desenvolver seu trabalho em diálogo com novas/outras propostas. Ou seja, há que se complementar a falta de qualidade na/da formação inicial, que não provê o docente de condições de reflexão para relacionar sua prática com disposições legais/normativas que se apresentam como novas. Assim, tanto as políticas curriculares quanto a formação "[...] se movem e se conectam a partir da falta compartilhada: qualidade, a primeira na intenção de reversão de um quadro de baixo desempenho e fracasso e a segunda como parte desse baixo desempenho" (FRANGELLA, 2020, p. 385).

É importante ainda mencionar que a Resolução CNE/CP no 2/2019 imprime mudanças significativas na formação de professores para a Educação Infantil, os Anos Iniciais do Ensino Fundamental e a Gestão Educacional. Historicamente, a formação destes profissionais sempre ocorreu nos Cursos de Pedagogia, porém as DCNCLPe (BRASIL, 2006b) não preveem habilitações para a formação do pedagogo, pois adotam a docência como base. A Resolução CNE/CP n 2/2019, por seu turno, não menciona os cursos de Pedagogia como o locus da formação, mas faz referência ao curso de formação de professores multidisciplinares da Educação Infantil e ao curso de formação de professores multidisciplinares dos Anos Iniciais do Ensino Fundamental, termos que, até a aprovação da BNC-Formação, não eram utilizados para descrever a formação destes docentes (GONÇALVES; MOTA; ANADON, 2020).

As análises evidenciam que a Resolução CNE/CP nº 2/2019 não tem compromisso com uma sólida formação teórica no campo das ciências humanas, ou seja, uma formação humana integral, omnilateral, sócio-histórica e cultural, pois seu interesse é "[...] formatar a classe trabalhadora às necessidades da classe burguesa, em especial às exigências do mercado de trabalho e do neotecnicismo por meio de suas categorias responsabilização, meritocracia e privatização" (FREITAS, 2012, p. 383). Assim, pela análise consubstanciada, evidencia-se, com base nesses silenciamentos, que o projeto é dificultar ou até mesmo acabar com o acesso do proletariado a todo o conhecimento cultural e historicamente construído. 
Em relação ao alinhamento dos PPCs das Licenciaturas em Pedagogia à Resolução CNE/CP no 2/2019, há uma grande preocupação por parte de entidades, estudantes, professores e gestores: as DCNCLPe 2006 serão revogadas e em seu lugar será imposto uma diretriz ao CPe alinhada à Resolução CNE/CP nº 2/2019 e à BNCC? Ao que parece, é que se prenuncia para breve, pois ainda nos primeiros dias de novembro de 2020 o CNE divulgou sua agenda de trabalho e nela estava indicada, para o dia 09/11/20, reunião do Conselho Pleno por videoconferência envolvendo a "comissão" responsável pela "revisão das Diretrizes Curriculares Nacionais do Curso de Pedagogia". Entre os membros identificados na referida agenda constam: Augusto Buchweitz (PUC/RS - Letras), Fernando César Capovilla (USP), Luiz Roberto Liza Curi (CNE Presidente), Maria Helena Guimarães de Castro (CNE - Relatora), Mozar Neves Ramos (CNE), Suely Melo de Castro Menezes (Presidente da Fundação Ipiranga e do Sindicato de Escolas Particulares de Ensino do Pará) e Wiliam Ferreira da Cunha (UNB - Física). Embora o site do CNE informe que é possível participar das sessões públicas, as autoras desse escrito tiveram suas solicitações negadas sob a alegativa de que se tratava de uma "reunião interna", não sendo sequer autorizada a assistir sem participação a reunião.

Dessa forma, compreende-se que a resistência ativa é o caminho necessário para que a Resolução CNE/CP no 2/2019 não seja implementada nos cursos de formação de professores das IES desse país. Em vista disso, está-se de acordo com Farias (2019) sobre a importância de, no contexto educacional, combater este alinhamento da formação de professores à BNCC e o retrocesso na concepção de formação anunciado por esta Resolução impositiva.

\section{Provocações para a continuidade do debate}

Em relação às políticas curriculares, destaca-se que tanto as decisões políticas e administrativas quanto a promulgação de documentos curriculares são fortemente influenciadas pelo contexto político vivenciado no país e pela correlação de forças dos agentes globais, nacionais e locais que fomentam as políticas para a educação brasileira.

Desde a implantação da primeira Diretriz da Formação de Professores, instituída pela Resolução CNE/CP n $1 / 2002$, perpassando pela Resolução CNE/CP n ${ }^{\circ}$ 1/2006, que regulamenta o funcionamento dos cursos de Pedagogia, seguida da Resolução CNE/CP $n^{0} 2 / 2015$, que instituiu a formação inicial articulada à formação continuada de professores e evidenciou a importância da valorização docente, até, mais recentemente, 
com a Resolução CNE/CP n 2/2019, que, de forma impositiva, instituiu as diretrizes de formação inicial de professores, é notório que a dominação do sistema capitalista sobre os objetivos educacionais tem provocado grandes tensionamentos nos processos formativos de professores. Decerto que as disputas, os embates e as lutas de pesquisadores progressistas do país são constantes, mas, em sua maioria, os resultados de suas pesquisas e análises não são levados em contas na formulação de políticas para a educação, principalmente após o golpe jurídico-midiático-parlamentar de 2016.

Diante deste cenário, urge continuar resistindo e construindo um campo de formação de professores como intelectuais orgânicos, com autonomia e liberdade para elaborar as políticas públicas de currículo neste país. Não obstante, o que se percebe na Resolução CNE/CP no 2/2019 é justamente o contrário: o desrespeito à autonomia dos professores, dos estudantes e da Universidade, bem como à constituição histórica de seus processos formativos, que se deram por meio de licenciaturas cujas propostas pedagógicas buscavam instituir um currículo que agregasse as demandas sociais e culturais a uma formação crítica, autônoma, reflexiva e emancipadora, ou seja, com uma práxis formativa para a cidadania democrática.

\section{Referências}

ASSOCIAÇÃO NACIONAL PELA FORMAÇÃO DOS PROFISSIONAIS DA EDUCAÇÃ̃O - ANFOPE. Políticas de formação e valorização dos profissionais da Educação: conjuntura nacional avanços e retrocessos. Documento final do XVIII Encontro Nacional da Anfope. Goiânia: ANFOPE, 2016. Disponível em: http://www.anfope.org.br/documentos-finais/. Acesso em: 20 set. 2020.

BALL, Stephen. Como as escolas fazem política: atuação em escolas secundárias. Ponta Grossa: Editora UEPG, 2016.

BRANDT, Andressa Graziele; HOBOLD, Márcia de Souza. Mudanças e continuidades dos marcos legais do curso de Pedagogia no Brasil. Revista Internacional de Educação Superior, Campinas, SP, v. 5, p. e019027, 2019. Disponível em: https://doi.org/10.20396/riesup.v5i0.8652576. Acesso em: 23 set. 2020.

BRANDT, Andressa Graziele; HOBOLD, Márcia de Souza. Trajetórias do curso de Pedagogia no Brasil. 1. ed. Curitiba, PR: CRV, 2020. v. 1000. 344p.

BRASIL. Lei n ${ }^{\circ}$ 9.394, de 20 de dezembro de 1996. Estabelece as diretrizes e bases da educação nacional. Diário Oficial da União: Brasília, DF, Seção 1, p. 27833, 23 dez. 1996. 
BRASIL. Conselho Nacional de Educação. Conselho Pleno. Parecer $n^{\circ} 5$, de 13 de dezembro de 2005. Institui Diretrizes Curriculares Nacionais para o Curso de Pedagogia. Diário Oficial da União: Brasília, DF, Seção 1, p. 10, 15 mai. 2006.

BRASIL. Conselho Nacional de Educação. Conselho Pleno. Parecer $n^{\circ} 3$, de 21 de fevereiro de 2006a. Institui Diretrizes Curriculares Nacionais para o Curso de Pedagogia. Diário Oficial da União: Brasília, DF, 11 mar. 2006.

BRASIL. Conselho Nacional de Educação. Conselho Pleno. Resolução ${ }^{\circ}{ }^{1}$, de 15 de maio de 2006b. Institui Diretrizes Curriculares Nacionais para o Curso de Graduação em Pedagogia, licenciatura. Diário Oficial da União: Brasília, DF, Seção 1, p. 11, 16 mai. 2006.

BRASIL. Conselho Nacional de Educação. Câmara de Educação Superior. Parecer $\mathrm{n}^{\circ}$ 133, de 30 janeiro de 2001. Esclarecimentos quanto à formação de professores para atuar na Educação Infantil e nos Anos Iniciais do Ensino Fundamental. Diário Oficial da União: Brasília, DF, Seção 1, p. 10, 6 mar. 2001.

BRASIL. Ministério da Educação. Conselho Nacional de Educação. Conselho Pleno. Resolução $n^{\circ} 2$, de $1^{\circ}$ de julho de 2015. Define as Diretrizes Curriculares Nacionais para a formação inicial em nível superior (cursos de licenciatura, cursos de formação pedagógica para graduados e cursos de segunda licenciatura) e para a formação continuada. Diário Oficial da União: Brasília, DF, Seção 1, p. 8-12, 2 jul. 2015.

BRASIL. Ministério da Educação. Conselho Nacional dos Secretários da Educação; União Nacional dos Dirigentes Municipais de Educação. Base Nacional Comum Curricular (BNCC). Educação é a Base. MEC/CONSED/UNDIME. Brasília: MEC, 2017. Disponível em: http://basenacionalcomum.mec.gov.br/images/BNCC_EI_EF _110518_versaofinal_site.pdf. Acesso em: 17 set. 2020.

BRASIL. Ministério da Educação. Conselho Nacional de Educação. Conselho Pleno. Resolução n ${ }^{\circ}$, de 20 de dezembro de 2019. Define as Diretrizes Curriculares Nacionais para a Formação Inicial de Professores para a Educação Básica e institui a Base Nacional Comum para a Formação Inicial de Professores da Educação Básica (BNC-Formação). Diário Oficial da União: Brasília, DF, Seção 1, p. 46-49, 15 abr. 2020.

DINIZ-PEREIRA. Júlio Emílio. Formação de professores: pesquisas, representações e poder. Belo Horizonte: Autêntica, 2000.

DOURADO, Luiz Fernandes. Políticas e gestão da Educação Básica no Brasil: limites e perspectivas. Educ. Soc., Campinas, v. 28, n. 100, p .921-946, out. 2007. Disponível em: https://bit.ly/3pzAlPE. Acesso em: 11 out. 2020.

DOURADO, Luiz Fernandes. Diretrizes Curriculares Nacionais para a Formação Inicial e Continuada dos Profissionais do Magistério da Educação Básica: concepções e desafios. Educação \& Sociedade, Campinas, v. 36, no. 131, p. 299-324, abr.jun. 2015. Disponível em: https://bit.ly/35IDxRm. Acesso em: 12 ago. 2020. 
Curso de Pedagogia em cenário de (contra)reforma:

Concepções de formação de professores em disputa

EVANGELISTA, Olinda. Apontamentos para o trabalho com documentos de política educacional. In: ARAUJO, Ronaldo M. L.; RODRIGUES, Doriedson S. (org.). A pesquisa em trabalho, educação e políticas educacionais. 1. ed. Campinas, SP: Alínea, 2012. v. 1, p. 52-71.

EVANGELISTA, Olinda; TRICHES, Jocemara. Curso de Pedagogia, organizações multilaterais e o superprofessor. Educ. Rev., Curitiba, n. 45, p. 185-198, set. 2012. Disponível em: https://bit.ly/2UF6dV2. Acesso: 6 nov. 2020.

EVANGELISTA, Olinda; FIERA, Letícia; TITTON, Mauro. Diretrizes para formação docente é aprovada na calada do dia: mais mercado. Universidade à esquerda: jornal independente e socialista, [S. l.], 14 nov. 2019. Disponível em: https://bit.ly/3f8GVrG. Acesso em: 20 mar. 2020.

FARIAS, Isabel Maria Sabino de. Inovação, mudança e cultura docente. Brasília: Liber Livro, 2006.

FARIAS, Isabel Maria Sabino de. O discurso curricular da proposta para BNC da formação de professores da Educação Básica. Revista Retratos da Escola, Brasília, v. 13, n. 25, p. 155-168, jan./maio 2019. Disponível em: https://bit.ly/2KITJ2A. Acesso em: 24 ago. 2020.

FARIAS, Isabel Maria Sabino de; SALES, Josete de Oliveira Castelo Branco; BRAGA, Maria Margarete Sampaio de Carvalho; FRANÇA, Maria do Socorro Lima Marques. Didática e docência: aprendendo a profissão. 4. ed. Brasília: Liber Livro, 2014.

FRANGELLA, Rita de Cássia Prazeres. Formação de professores em tempos de BNCC: um olhar a partir do campo do currículo. Formação em Movimento, [S. l.], v .2, n. 4, p. 380-394, jul./dez. 2020. 382. Disponível em: https://bit.ly/3pDAPnX. Acesso em: 23 set. 2020.

FREITAS, Luiz Carlos. Os reformadores empresariais da educação: da desmoralização do magistério à destruição do sistema público de educação. Educação \& Sociedade, Campinas, v. 33, n. 119, p. 379-404, abr./jun. 2012. Disponível em: https://bit.ly/35FPfMs. Acesso em: 24 set. 2020.

FREITAS, Luiz Carlos. Política educacional e base nacional II. Avaliação educacional, [São Paulo], 18 set. 2015. Disponível em: https://bit.ly/3fa9sNz. Acesso em: 3 set. 2020.

FREITAS, Helena Costa Lopes de. Formação de professores no Brasil: 10 anos de embate entre projetos de formação. Educação \& Sociedade, Campinas, v. 23, n. 80, p.136-167, set. 2002. Disponível em: https://www.scielo.br/pdf/es/v23n80/12928.pdf. Acesso em: 12 set. 2020. 
FRIGOTTO, Gaudêncio. Os circuitos da história e o balanço da educação no Brasil na primeira década do século XXI. Rev. Bras. Educ., Rio de Janeiro, v. 16, n. 46, p. 235254, 2011. Disponível em: https://bit.ly/32X9OCf. Acesso em: 22 set. 2020.

GONÇALVES, Suzane da Rocha Vieira; MOTA, Maria Renata Alonso; ANADON, Simone Barreto. A resolução $\mathrm{CNE} / \mathrm{CP} \mathrm{n}^{\circ}$ 2/2019 e os retrocessos na formação de professores. Formação em Movimento, Rio de janeiro, RJ, v. 2, i. 2, n. 4, p. 360-379, jul./dez. 2020. Disponível em: https://doi.org/10.38117/2675181X.formov2020.v2i2n4.360-379. Acesso em: 24 set. 2020.

HYPOLITO, Álvaro Luiz M. Trabalho docente e o novo Plano Nacional de Educação: valorização, formação e condições de trabalho. Cad. Cedes, Campinas, v. 35, n. 97, p. 517-534, set./dez. 2015. Disponível em: https://bit.ly/3kIkI50. Acesso em: 23 set. 2020.

HOBOLD, Márcia de Souza; AGUIAR, Maria Aparecida de; JUNCKES, Rosane Santana; CORDEIRO, Aliciene Fusca Machado. As diretrizes curriculares nacionais dos cursos de pedagogia para a formação docente: processo de implantação da Resolução CNE/CP n ${ }^{\circ} 1 / 2006$. Psic. da Ed., São Paulo, n. 28, p. 151-168, $1^{\circ}$ sem. 2009. Disponível em: https://bit.ly/3nwcuhS. Acesso em: 20 set. 2020.

NÓBREGA-THERRIEN, Silvia Maria; FARIAS, Isabel Maria Sabino de; SALES, José Albio Moreira de. Trilhas do labirinto na pesquisa educacional qualitativa: dos procedimentos de coleta de dados ao trabalho de campo. In: FARIAS, Isabel Maria Sabino de; NUNES, João Batista Carvalho; NÓBREGA-THERRIEN, Silvia Maria (org.). Pesquisa científica para iniciantes: caminhos do labirinto. Fortaleza: EdUECE, 2010, v.1, p. 53-66.

PIMENTA, Selma Garrido; FUSARI, José Cerchi; PEDROSO, Cristina Cinto Araujo; PINTO, Umberto de Andrade. Os cursos de licenciatura em pedagogia: fragilidades na formação inicial do professor polivalente. Educação e Pesquisa, São Paulo, v. 43, n. 1, p.15-30, jan./mar. 2017.

RAMOS, Marise Nogueira. A pedagogia das competências: autonomia ou adaptação? São Paulo: Cortez, 2001. 320p.

RODRIGUES, Larissa Zancan; PEREIRA, Beatriz; MOHR, Adriana. O Documento "proposta para Base Nacional Comum da Formação de Professores da Educação Básica" (BNCFP): dez razões para temer e contestar a BNCFP. Revista Brasileira de Pesquisa em Educação em Ciências, Belo Horizonte, n 20, 1-39, jan. 2020. Disponível em: https://bit.ly/2UGQ4OC. Acesso em: 20 mar. 2020.

SAVIANI, Dermeval. Pedagogia: o espaço da educação na universidade. Cadernos Pesquisa, São Paulo, v. 37, n. 130, p. 99-134, 2007. Disponível em: https://bit.ly/3pBLfVj. Acesso em: 17 set. 2019.

SCHEIBE, Leda; DURLI, Zenilde. Curso de Pedagogia no Brasil: olhando o passado, compreendendo o presente. Educação em Foco, Belo Horizonte, Ano 14, n. 17, p. 79109, jul. 2011. Disponível em: https://bit.ly/3fal3vS. Acesso em: 19 jan. 2016. 
SHIROMA, Eneida O.; EVANGELISTA, Olinda. A colonização da utopia nos discursos sobre profissionalização docente. Revista Perspectiva, Florianópolis, v. 22, n. 2, p. 525545, jul./dez. 2004. Disponível em: https://bit.ly/3f9YKXp. Acesso em: 10 set. 2020.

SHIROMA, Eneida; EVANGELISTA, Olinda. Avaliação e responsabilização pelos resultados: atualizações nas formas de gestão de professores. Revista Perspectiva, Florianópolis, v. 29, n. 1, p. 127-160, jan./jun. 2011. Disponível em: https://bit.ly/36MyFKf. Acesso em: 10 set. 2020.

TRICHES, Jocemara. A internalização da agenda do capital em Cursos de Pedagogia de Universidades Federais (2006-2015). Tese (Doutorado em Educação) - Universidade Federal de Santa Catarina, Florianópolis, 2016.

*Andressa Graziele Brandt é doutora e Mestre em Educação pelo Programa de PósGraduação em Educação (PPGE), da Universidade Federal de Santa Catarina (UFSC). Graduada em Pedagogia pela Universidade Regional do Noroeste do Estado do Rio Grande do Sul (Unijuí). Pedagoga e Professora da área de Pedagogia do Instituto Federal Catarinense (IFC) - Campus Camboriú. Integrante do Grupo de Estudos e Pesquisas Formação de Professores e Práticas de Ensino (Foppe) (UFSC/CNPq). Site: https://foppe.ufsc.br/artigos/. Integrante do Grupo de Pesquisas interdisciplinares: Educação, saúde e Sociedade(UEMA/CNPq). Autora da obra "Trajetórias do Curso de Pedagogia no Brasil”, em conjunto com a professora Márcia de Souza de Hobold.

E-mail: andressa.brandt@ifc.edu.br; andressabrandt@hotmail.com

ORCID: https://orcid.org/0000-0002-8176-1930

**Márcia de Souza Hobold tem Pós-Doutoramento em Educação, com bolsa do CNPq-PDJ. Doutora em Educação pela PUC SP. Professora do Programa de Pós-Graduação em Educação - PPGE e do Departamento de Metodologia de Ensino - MEN, do Centro de Ciências da Educação (MEN/CED), da Universidade Federal de Santa Catarina (UFSC). É líder do Grupo de Estudos e Pesquisas: Formação de Professores e Práticas de Ensino - FOPPE; pesquisadora vinculada ao Grupo de Trabalho (GT 8) de Formação de Professores da ANPEd Nacional; e, membro da Rede Interinstitucional de Pesquisas sobre a Formação e as Práticas Docentes - RIPEFOR.

E-mail: $\underline{\text { marcia.hobold@ufsc.br }}$

Orcid: https://orcid.org/0000-0002-4179-608X 
*** Isabel Maria Sabino de Farias tem Pós-Doutoramento em Educação pela Universidade de Brasília (UnB). Doutora em Educação Brasileira (UFC). Pedagoga (UECE). Professora do Centro de Educação e do Programa de Pós-Graduação em Educação (PPGE) da Universidade Estadual do Ceará (UECE). Líder do grupo de pesquisa Educação, Cultura Escolar e Sociedade (EDUCAS/CNPq); pesquisadora vinculada ao Grupo de Trabalho (GT 8) Formação de Professores da ANPEd Nacional; Coordenadora do Observatório Desenvolvimento Profissional Docente e Inovação Pedagógica.

E-mail: isabel.sabino@uece.br

Orcid: https://orcid.org/0000-0003-1799-0963 